\title{
Supratentorial Glioblastoma With Spinal Cord Intramedullary Metastasis
}

\author{
Mark G. Hamilton, Bruce I. Tranmer and Neil A. Hagen
}

\begin{abstract}
A patient presented with myelopathy due to intramedullary thoracic spinal cord glioblastoma 10 months after treatment for a supratentorial glioblastoma. There was no supratentorial recurrence, and no evidence of gross leptomeningeal dissemination documented by CSF cytology, complete myelography, and MRI imaging. Gross examination of the spinal cord and arachnoid at the time of exploratory thoracic spinal surgery was normal. However. histological review of thoracic arachnoid demonstrated microscopic deposits of glial fibrillary acidic protein (GFAP) positive tumour consistent with malignant astrocytoma. Intramedullary spinal cord metastasis of cerebral glioblastoma rarely occurs, but may develop in association with leptomeningeal tumour dissemination. As local control of primary tumours improves, distant metastasis is likely to become a more common clinical problem. Leptomeningeal gliomatosis may be very difficult to document, even when clinically suspected and GFAP staining of a biopsy of arachnoid tissue can play an important role in confirming the diagnosis. This information can be critical to establish prognosis and develop an appropriate treatment strategy.
\end{abstract}

RÉSUMÉ: À propos d'un cas de glioblastome supratentoriel avec métastase intramédullaire à la moelle épinière. Un patient s'est présenté avec une myélopathie due à un glioblastome intramédullaire de la moelle épinière thoracique, 10 mois après avoir été traité pour un glioblastome supratentoriel. Il n'y avait pas de récidive supratentorielle et pas d'évidence flagrante de dissémination leptoméningée à la cytologie du LCR, à la myélographie complète et à l'imagerie par MRI. Un examen superficiel de la moelle épinière et de l'arachnoid: au moment de la chirurgic spinale thoracique exploratrice était normal. Cependant, une révision de l'histologie de l'arachnoide thoracique a montré des dépots microscopiques de tumeur GFAP positive compatibles avec un astrocytome malin. Les métastases spinales intramédullaires d'un glioblastome cérébral surviennent rarement, mais peuvent se développer en association avec une dissémination tumorale leptoméningée. Avec l'amélioration du contrôle local des tumeurs primaires, les métastases à distance sont susceptibles de devenir un problème clinique plus fréquent. Une gliomatose leptoméningée peut être très difficule à documenter, même quand on la soupçonne cliniquement et la coloration par le GFAP d'une biopsie de tissu arachnoïdien peut jouer un rôle important dans la confirmation du diagnostic. Cette information peut être critique pour établir le prognostic et développer une stratégie de traitement appropriée.

Can. I. Neurol.Sci. 1993: 20:65-68

Symptomatic leptomeningeal metastasis occurs in a significant minority of patients with supratentorial malignant glioma, whereas intramedullary spinal cord metastasis is very uncommon. ${ }^{1.3}$ We present a patient with myelopathy from metastatic supratentorial malignant glioma who had concurrent but initially asymptomatic leptomeningeal metastasis. The appearance of symptons referable to an intrinsic cord lesion in a patient treated for supratentorial glioblastoma presents a diagnostic challenge, and raises questions concerning the biology of such a tumour.

\section{CASE REPORT}

A 70-year-old, right handed man presented in August 1989 with headache and a progressive left hemiparesis. A contrast enhanced CT scan of the head demonstrated a large ring enhancing lesion in the right frontal lobe (Figure 1A). He underwent a gross total resection of a glioblastoma multiforme (Figure 2A) followed by conventional radiotherapy, and experienced a complete recovery of function. Follow-up contrast enhanced CT at 6 months demonstrated no evidence of tumour recurrence.

Ten months after surgery, he presented with a three-week history of progressive weakness and numbness of both legs, bladder difficulty, and headache. Physical examination was initially consistent with a mild cauda equina or conus syndrome. Over several days. he developed an incomplete paraparesis with typical upper motor neuron signs, and a T 10 sensory level.

A contrast enhanced CT scan of the head demonstrated no evidence of local tumour recurrence and no periventricular enhancement. Cerebrospinal fluid (CSF) examination for cylology, on three separate occasions, failed to identify any abnormal cells. However. CSF protein was consistently greater than $2.5 \mathrm{~g} / \mathrm{L}$ (normal range: $0.15-0.45 \mathrm{~g} / \mathrm{L}$ ). The remainder of the CSF examination was unremarkable. A complete myelogram and postmyelographic CT of the lower thoracic spine were unremarkable. Spinal MR imaging demonstrated diffuse increased T2 signal in the spinal cord at the T9-T10 levels (Figure IB). There was no

Department of Clinical Neurosciences, Foothills Hospital (M.G.H., B.I.T., N.A.H.)

Brain Tumour Group, Tom Baker Cancer Centre (N.A.H.), University of Calgary, Calgary

Received May 1, 1992. Accepted in final form October 5, 1992

Reprint requests to: Mark G. Hamilton, M.D.C.M., c/o Editorial Office, Barrow Neurological Institute, 350 West Thomas Road, Phoenix, Arizona. USA 85013 
other abnormality present with MR imaging. Paramagnetic contrast had not been approved for use in Canada when this patient presented. The preoperative clinical impression was an intraxial spinal tumour at the T10 level.

At operation to determine the etiology of the spinal cord lesion, the cord appeared distended but was otherwise normal in appearance. A midline myelotomy revealed a moderately vascular tumour which was pathologically consistent with malignant astrocytoma (Figure 2B). A biopsy of the arachnoid tissue, which was grossly normal in appearance, demonstrated microscopic deposits of tumour cells which were strongly glial fibrillary acidic protein (GFAP) positive (Figure 3). Postoperative spinal radiotherapy was initiated. During therapy, the patient developed hydrocephalus which was treated with a ventricular drain. He ultimately died as a consequence of overwhelming sepsis. Autopsy was refused.

\section{Discussion}

The neuroaxis spread of supratentorial glioblastoma multiforme (GBM) was once thought to be a rare event. ${ }^{2.3}$ However, recent patient series have identified postmortem evidence of CSF spread occurring in $4 \%-20 \%$ of patients, ${ }^{1-4}$ with symptomatic metastasis occurring in at least $2 \%-4 \%$ of patients. ${ }^{3.5}$ The reasons for the apparent increase in the incidence of this problem have not been conclusively identified but may be related to the increasing survival in patients with malignant brain tumour, or potentially to changes in the biological properties of tumours occurring as a result of surgery, radiation therapy, or chemotherapy. ${ }^{3,5,6}$ Premortem diagnosis is usually based on clinical presentation, CSF cytology and radiological investigations (myelography or MRI). However, establishing this diagnosis often remains a difficult exercise. Prognosis is generally dismal, with survival averaging 2-3 months after the diagnosis of leptomeningeal dissemination is made. ${ }^{3}$

The pathological examination of patients with cerebrospinal fluid spread of GBM seldom identifies invasion of the spinal cord. ${ }^{2.3}$ More common is the finding of extramedullary spinal cord compression with invasion of spinal nerve roots. ${ }^{2}$ However, we felt that this was the likely etiology of our patient's spinal cord tumour. Erlich and Davis described two autopsy reports of spinal cord infiltration from contiguous leptomeningeal deposits of metastatic GBM, and identified 5 other patients reported in the literature with co-existent leptomeningeal, disease and intramedullary metastasis.' In a clinical paper, Vertosick and Selker identified two patients with antemortem diagnosis of intramedullary tumour and concomitant leptomeningeal metastasis. ${ }^{3}$ Because the predominant symptoms in these patients were due to leptomeningeal disease, and intramedullary metastasis from the cerebral GBM tumours were strongly associated with subarachnoid metastases, it is tempting to speculate that intramedullary metastasis is caused by contiguous extension of coexistent, typically bulky leptomeningeal disease, rather than by hematogenous dissemination. An alternative explanation is that the spinal cord tumour was a multicentric event not directly associated with the previous cerebral lesion. GBM multicentricity of intracranial glial tumours has been estimated to occur with a frequency of $4.5 \%$ macroscopically and $6 \%$ microscopically. ${ }^{2}$ However, there has been no report of a patient with supratentorial GBM and a multicentric spinal cord deposit of GBM or malignant astrocytoma. Given the microscopic tumour deposits which were identified in the spinal arachnoid, the authors do not consider this a realistic possibility for this patient.

Additional insight into the pathophysiology of intramedullary metastasis from GBM is provided by our patient. The arachnoid tumour deposits, premorbid hydrocephalus and elevated CSF protein provided clinical evidence suggestive of leptomeningeal gliomatosis. The negative CSF cytology, myelogram, MR imaging, and direct inspection of the arachnoid were
A

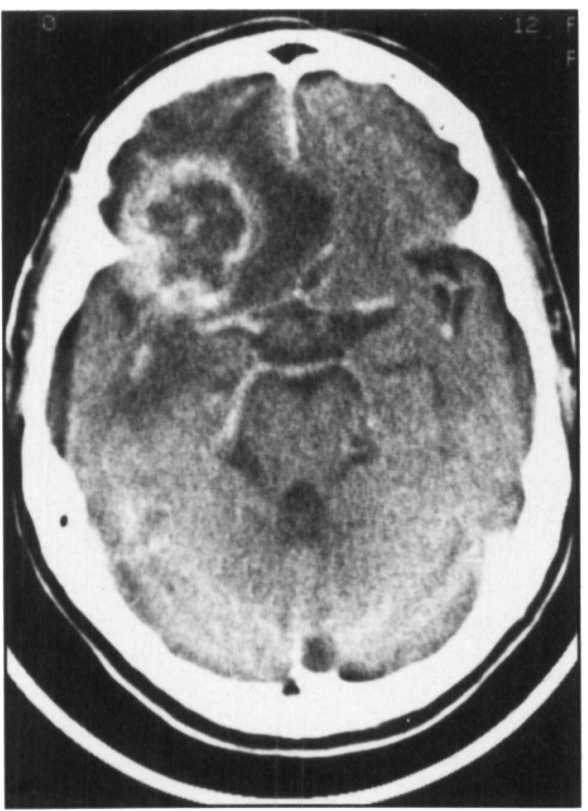

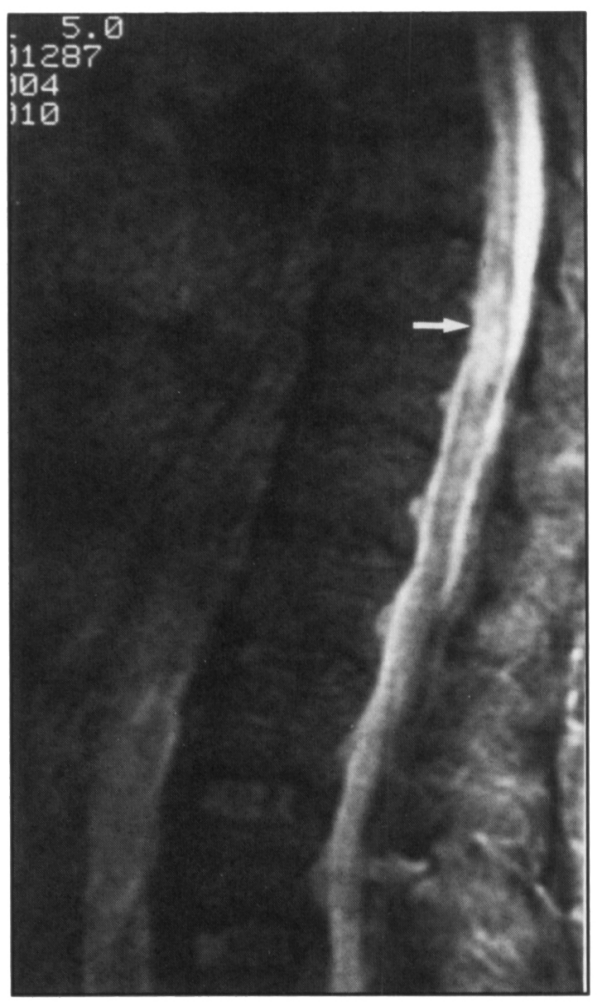

Figure I-Radiology. A. CT scan (enhanced): Large right frontal lobe lesion; ring enhancing with surrounding edema. B. MRI Scan: diffusely increased T2 signal in spinal cord at T9 and T10 (arrow). 


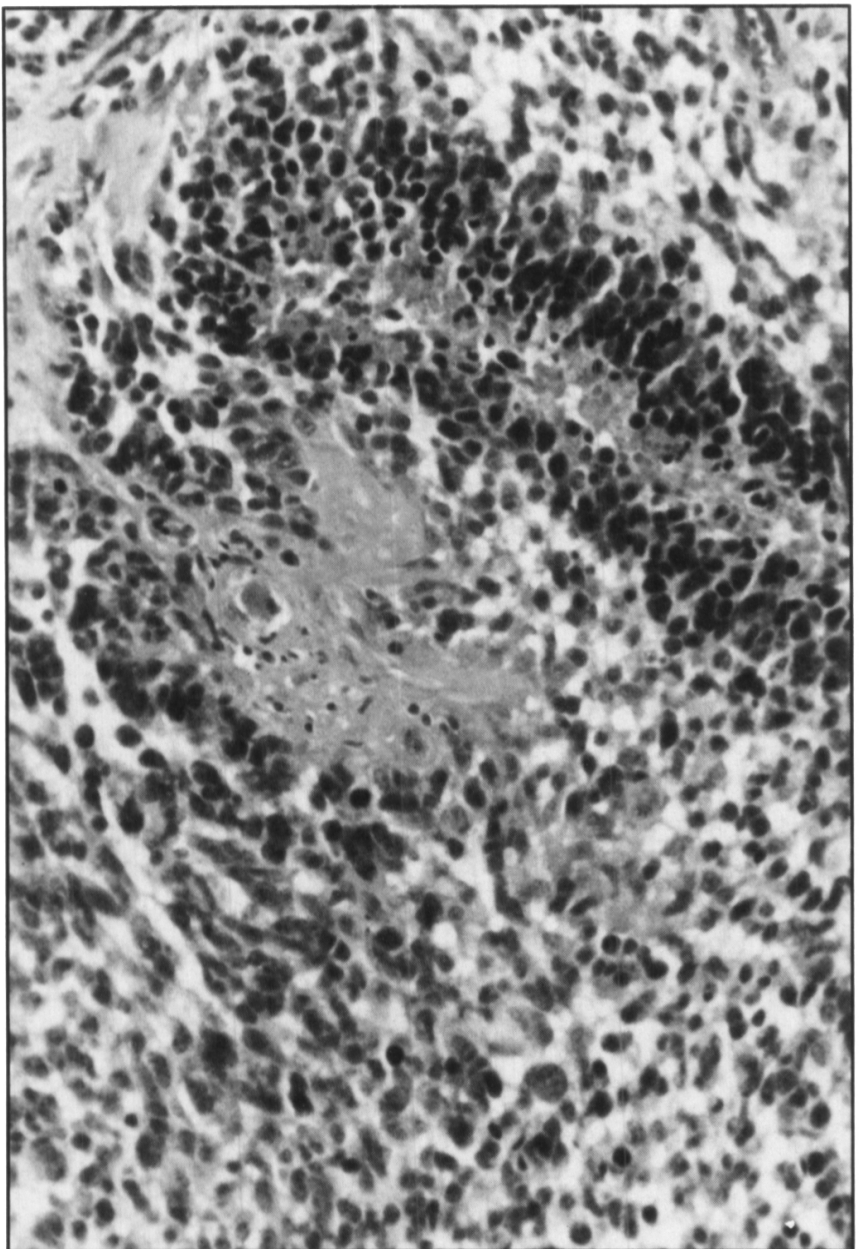

A

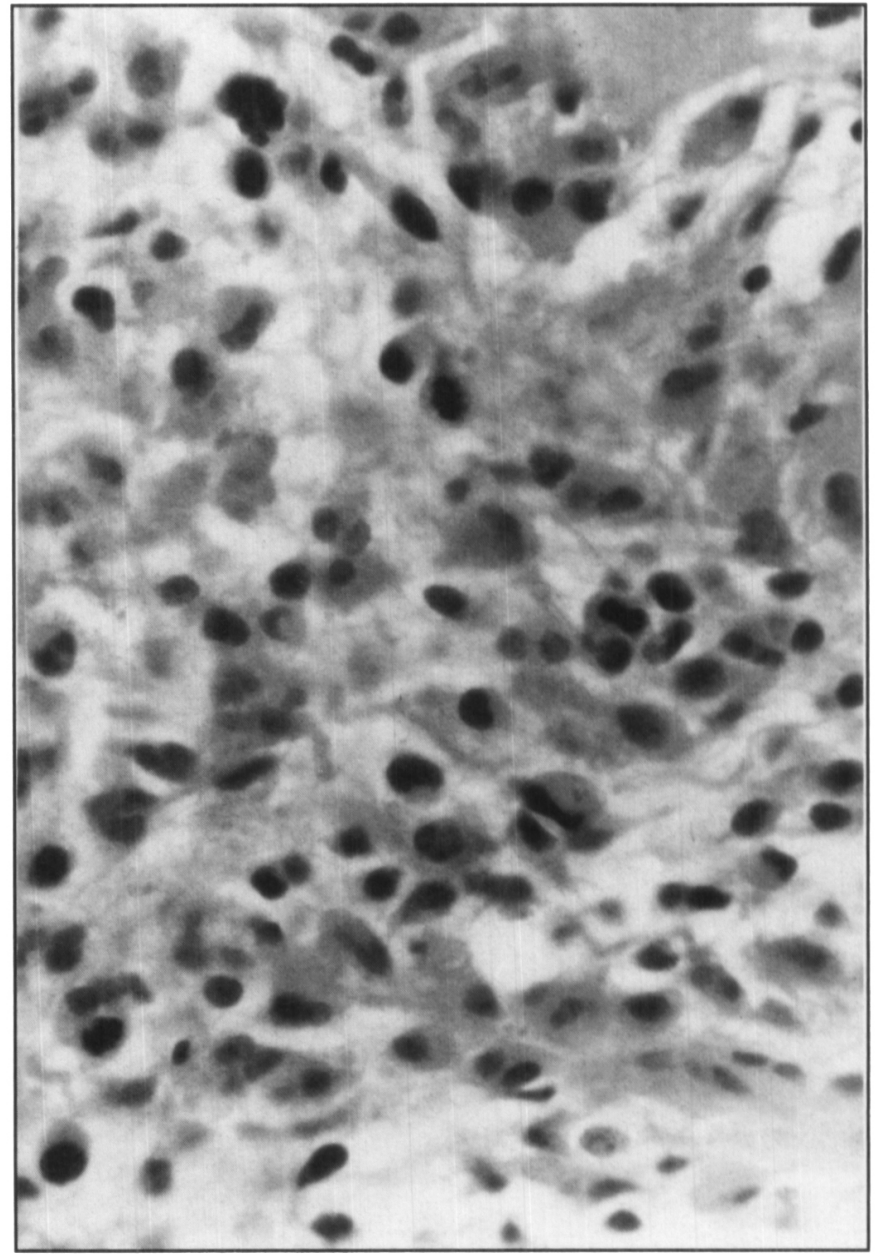

B

Figure 2 - Tumour pathology. A. Pathology ( $H$ \& E Stain $\times 1000$; from right frontal lobe): glial tumour: Marked increased cellularity. itascular proliferation, muclear pleomorphism and frequent mitotic figures, with pseudopallisading and necrosis. Pathological diagnosis: glioblastoma multiforme. B. Pathology (H \& E Stain $\times 2000$ from low thoracic spinal cord): glial numour. Marked increased cellularity. muclear pleomorphism and frequent mitotic figures. No pseudopallisading. necrosis. or vascular proliferation. Pathological diagnosis: malignamt astrocytoma.

all evidence that there was no bulky meningeal spread. This suggests that, while leptomeningeal gliomatosis may be a necessary accompaniment of intramedullary metastasis, symptoms from meningeal disease may be very mild. We speculate that the intramedullary deposit arose from direct microscopic spread of subarachnoid metastasis.

This report also illustrates the difficulty frequently encountered in establishing a clinical diagnosis of leptomeningeal metastasis. Vertosick and Selker have identified the importance of using paramagnetic enhancement with spinal MR imaging of patients suspected to have leptomeningeal tumour spread. ${ }^{3}$ While we were unable to use a contrast agent during this patient's MRI scan, the combination of the MRI and the myelogram identified no bulky leptomeningeal tumour deposits. The presence of tumour cells in the arachnoid allowed confirmation of the metastatic origin of the spinal cord tumour even though there was no gross evidence of contiguous spread from the subarachnoid space to the intramedullary tumour location. The use of the GFAP stain was quite helpful in the pathological diagnosis of the arachnoid tumour. We are uncertain whether an enhanced spinal MRI study would have been able to identify these microscopic tumour deposits, but we do suggest that this investigation be performed in any patient with a similar presentation.

Following resection of supratentorial GBM, gliomatous meningitis tends to occur in younger patients who have a longer than average survival time. ${ }^{3.6 .7}$ This may be a reflection of the general overall poor prognosis of supratentorial GBM in older patients, related to its rapid local spread, and the somewhat longer duration required for leptomeningeal dissemination 10 develop. While our patient was not young, his clinical course is in keeping with this principle of long survival in that he lived 12 months after initial diagnosis with no evidence of local cerebral recurrence.

\section{SUMMARY}

In summary, we have described the case of a 70-year-old male who presented 10 months after resection and irradiation of a cerebral glioblastoma multiforme with an intramedullary malignant astrocytoma of the thoracic spinal cord. Unenhanced 


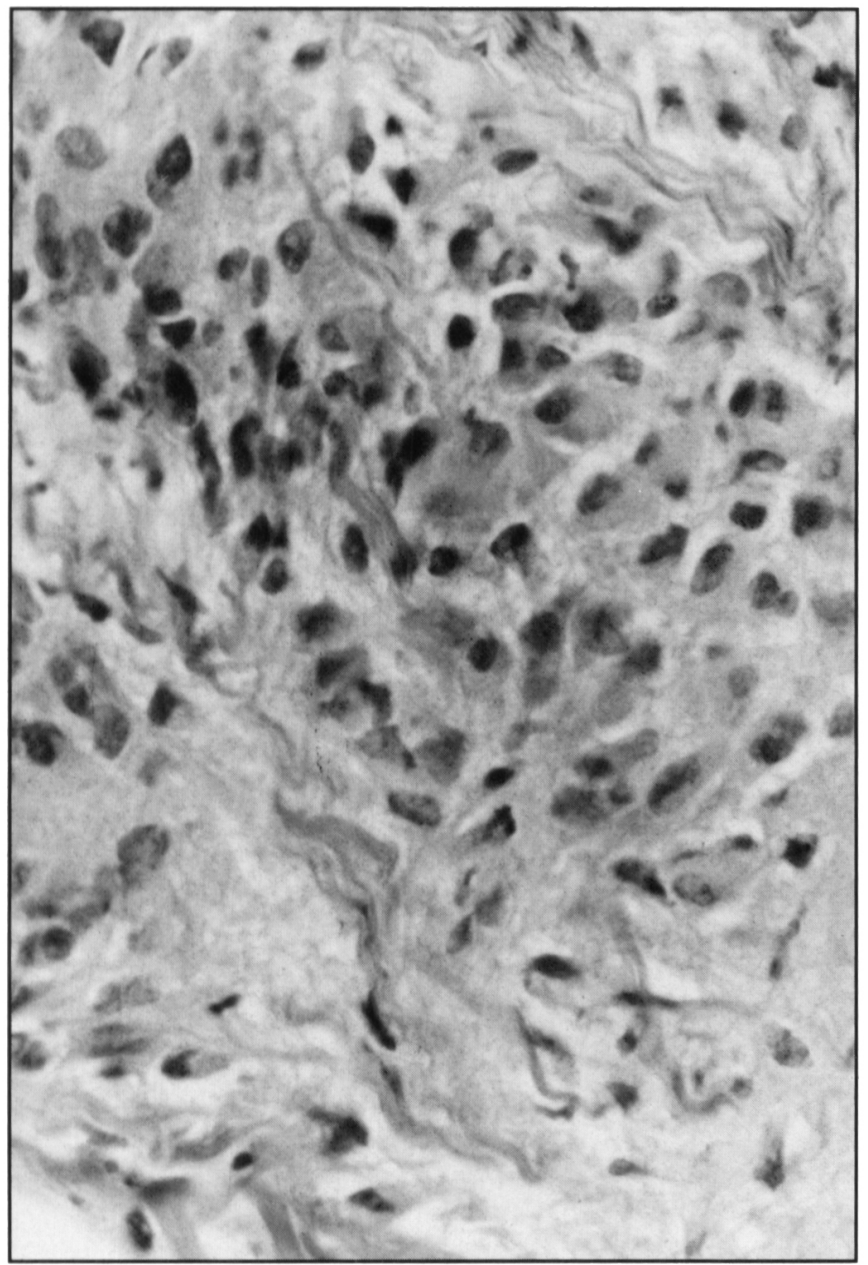

A

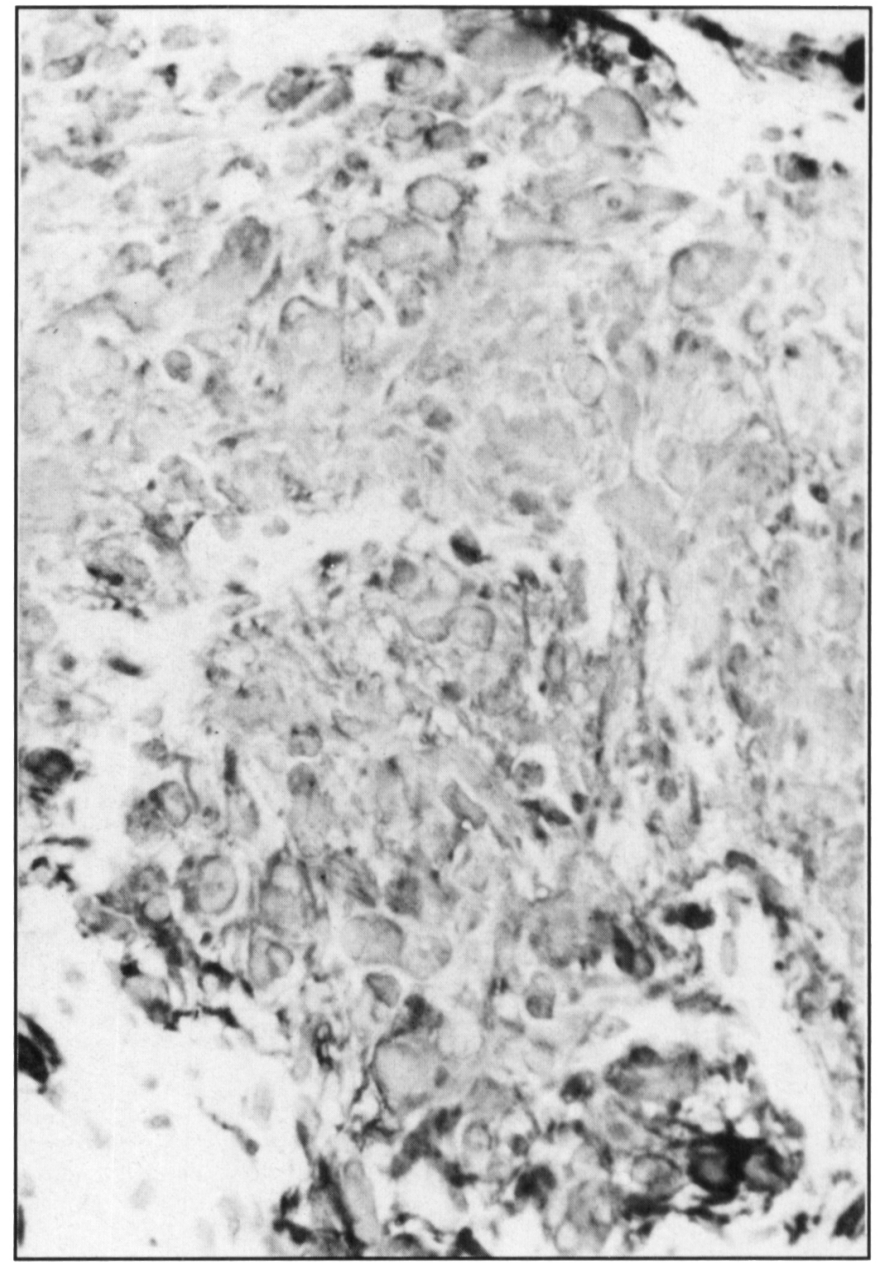

B

Figure 3 - Arachnoid biopsy. A. Pathology (H.\& E. Stain, $\times 2000$; arachnoid biopsy): glial tumour. Marked increased cellularity with nuclear pleomorphism. Similar appearance to Figure 2B. Diagnosis: malignant astrocytoma. B. Pathology (GFAP Stain, $\times 2000 ;$ arachnoid biopsy): all cells which appear in this image stain positive.

MR imaging, a complete myelogram and operative exploration failed to document the presence of bulky leptomeningeal gliomatosis. However, arachnoid biopsy with GFAP staining demonstrated microscopic tumour deposits and helped establish the origin of the intramedullary tumour. It is possible that enhanced MR imaging or postmortum examination may have been able to identify macroscopic extramedullary tumour deposits. Notwithstanding this possibility, this patient's case does illustrate the possibility of intramedullary spinal metastasis from a supratentorial glioblastoma in the absence of any evidence of gross extramedullary tumour. In addition, arachnoid biopsy with GFAP staining may help establish the origin of a spinal cord tumour in instances where the standard diagnostic modalities fail to demonstrate leptomeningeal gliomatosis. This information would assist with treatment planning and help establish a prognosis for the affected patient.

\section{REFERENCES}

1. Erlich SS, Davis RL. Spinal subarachnoid metastasis from primary intracranial glioblastoma multiforme. Cancer 1978; 42: 28542864.
2. Russell DS, Rubinstein LJ. Pathology of tumours of the nervous system. In: Russell DS, Rubinstein LJ, eds. Pathology of the Nervous System. Baltimore: Williams and Wilkins, 5th Ed. 1989; 222-223, 244-247, 421-448.

3. Vertosick FT, Selker RG: Brainstem and spinal metaslases of supratentorial glioblastoma multiforme: a clinical series. Neurosurgery 1990; 27: 516-522.

4. Salazar OM, Rubin P. The spread of glioblastoma multiforme as a determining factor in the radiation treated volume. In $\mathrm{J}$ Radiation Oncol Biol Phys 1976; 1: 627-637.

5. Delattre JY, Walker RW, Rosenblum MK. Leptomeningeal gliomatosis with spinal cord or cauda equina compression: a complication. of supratentorial gliomas in adults. Acta Neurol Scand 1989; 79: 133-139.

6. Yung WA, Horten BC, Shapiro WR. Meningeal gliomatosis: a review of 12 cases. Ann Neurol 1980; 8: 605-608.

7. Awad I, Bay JW, Rogers L. Leptomeningeal metastasis from supratentorial malignant gliomas. Neurosurgery 1986; 19: 247-251. 